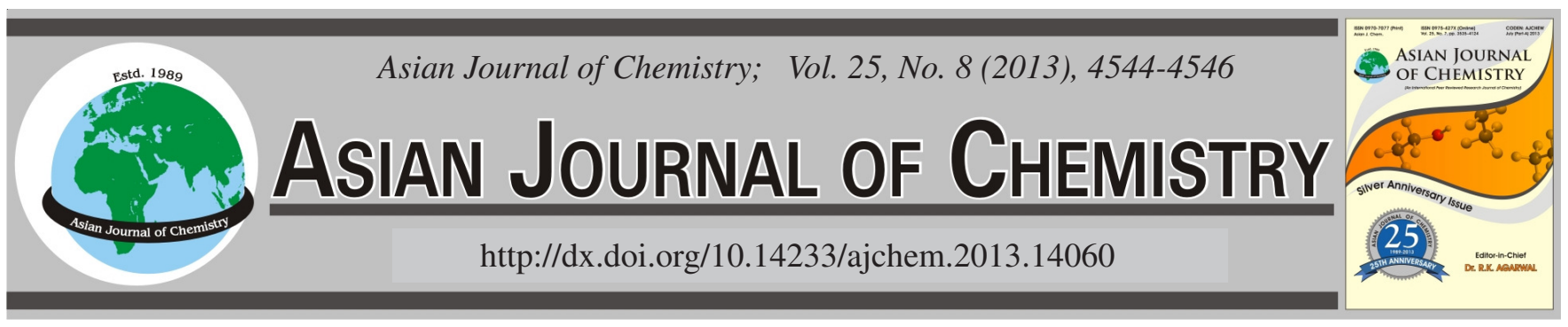

\title{
A Supramolecular Ni(II) Complex Based on a Bisoxime Compound: Synthesis and Crystal Structure
}

\author{
Yin-Xia Sun ${ }^{*}$, Xin-Ran Li, Wei-Sheng Meng, Xiao-Yan Zhang, Qing-Ying Lan, Fei-Xia Ma and Zong-Li Ren
}

School of Chemical and Biological Engineering, Lanzhou Jiaotong University, Lanzhou 730070, P.R. China

*Corresponding author: E-mail: sun_yinxia@163.com

\begin{abstract}
A new $\mathrm{Ni}(\mathrm{II})$ complex, $\left\{[\mathrm{NiL}(\mathrm{THF})]_{2}(\mu-\mathrm{OAc})_{2} \mathrm{Ni}\right\}\left(\mathrm{H}_{2} \mathrm{~L}=4,4^{\prime}\right.$-dibromo-2,2'-[(ethylene)dioxybis(nitrilomethylidyne)]diphenol), has been synthesized and characterized structurally. The results show that the complex consists of three $\mathrm{Ni}(\mathrm{II})$ atoms, two tetradentate $(\mu-\mathrm{L})^{2-}$ units, two coordinated $\mu$-acetate ions which coordinate to three $\mathrm{Ni}$ (II) atoms in $\mu \mathrm{Ni}-\mathrm{O}-\mathrm{C}-\mathrm{O}-\mathrm{Ni}$ mode and two coordinated THF molecules. All the hexa-coordinated $\mathrm{Ni}(\mathrm{II})$ atoms of the complex have a distorted octahedral geometry. The crystal packing of the complex shows that a notable feature of this structure resides in the formation of an infinite $2 \mathrm{D}$ supramolecular networks through intermolecular $\mathrm{C}-\mathrm{H} \cdots \mathrm{O}$ hydrogen-bonding and $\mathrm{C}-\mathrm{H} \cdots \pi$ interactions.
\end{abstract}

Key Words: Bisoxime ligand, Ni(II) complex, Supramolecular structure.

\section{INTRODUCTION}

Although some advance has been made in the studies of Salen-Ni(II) complexes ${ }^{1-3}$, it still seems there could be new and specific applications for such a unique group of compounds. To change the structures or improve the functions of the resulted complexes, chemical modifications of the elemental Salen-type ligand are effective and inevitable ${ }^{4-7}$. Herein, a new Ni(II) complex with a Salen-type bisoxime ligand based on O-alkyloxime instead of the imine moiety has been synthesized and structurally characterized by X-ray crystallography.

\section{EXPERIMENTAL}

5-Bromo-2-hydroxybenzaldehyde ( $\geq 98 \%$ ) was purchased from Alfa Aesar and used without further purification. The other reagents and solvents were analytical grade reagents from Tianjin Chemical Reagent Factory and were used without further purification. Elemental analysis for $\mathrm{Ni}$ was detected by an IRIS ER/S.WP-1 ICP atomic emission spectrometer. C, $\mathrm{H}$ and $\mathrm{N}$ analyses were carried out with a GmbH VariuoEL V3.00 automatic elemental analyzer. X-Ray single crystal structure determination was carried out on a Bruker Smart 1000 CCD area detector. Melting points were measured with a microscopic melting point apparatus made by the Beijing Taike Instrument Limited Company and the thermometer was uncorrected.
General procedure: 4,4'-Dibromo-2,2'-[(ethylene)dioxybis(nitrilomethylidyne)]diphenol $\left(\mathrm{H}_{2} \mathrm{~L}\right)$ was synthesized according to an analogous method reported earlier ${ }^{8}$.

A solution of $\mathrm{Ni}(\mathrm{II})$ acetate tetrahydrate $(2.5 \mathrm{mg}, 0.01$ $\mathrm{mmol})$ in ethanol ( $3 \mathrm{~mL})$ was added dropwise to a solution of $\mathrm{H}_{2} \mathrm{~L}$ (4.6 mg, $\left.0.01 \mathrm{mmol}\right)$ in $\mathrm{THF}(5 \mathrm{~mL})$ at room temperature. The colour of the mixing solution turned to pale-green immediately, the mixture was filtered and the filtrate was allowed to stand at room temperature for $c a$. 2 weeks, the solvent was partially evaporated and obtained green single crystals suit for X-ray crystallographic analysis. Anal. calcd. (\%) for $\mathrm{C}_{44} \mathrm{H}_{46} \mathrm{~N}_{4} \mathrm{O}_{14} \mathrm{Br}_{4} \mathrm{Ni}_{3}$ : C, 39.13; H, 3.43; N, 4.15; Ni, 13.04. Found (\%): C, 39.15; H, 3.45; N, 4.12; Ni, 12.87.

X-Ray structure determination: The single crystal of the $\mathrm{Ni}$ (II) complex, with approximate dimensions of $0.17 \mathrm{~mm}$ $\times 0.16 \mathrm{~mm} \times 0.06 \mathrm{~mm}$ was placed on a Bruker Smart 1000 diffractmeter equipped with Apex CCD area detector. The diffraction data were collected using a graphite monochromated $\mathrm{MoK}_{\alpha}$ radition $(\lambda=0.71073 \AA)$ at $298(2) \mathrm{K}$. The structure was solved by using the program SHELXS- $97^{9}$ and Fourier difference techniques and refined by full-matrix least-squares method on $\mathrm{F}^{2}$ using SHELXL-97 ${ }^{10}$. Details of the data collection and refinements of the Ni(II) complex are given in Table-1. The non-hydrogen atoms were refined anisotropically. Hydrogen atoms were added theoretically. CCDC: 876226. 


\begin{tabular}{ll}
\hline \multicolumn{1}{c}{ CRYSTAL DATA AND REFINEMENT } \\
\multicolumn{1}{c}{ PARAMETERS FOR THE Ni(II) COMPLEX } \\
\hline Empirical formula & $\mathrm{C}_{44} \mathrm{H}_{46} \mathrm{~N}_{4} \mathrm{O}_{14} \mathrm{Br}_{4} \mathrm{Ni}_{3}$ \\
Formula weight & 1350.62 \\
Temperature & $298(2) \mathrm{K}$ \\
Wavelength & $0.71073 \AA$ \\
Crystal system & Monoclinic \\
Space group & $\mathrm{Cc}$ \\
Unit cell dimensions & $\mathrm{a}=15.7493(16) \AA, \mathrm{b}=15.3900(16) \AA$ \\
Volume & $\mathrm{c}=21.738(2) \AA, \beta=101.027(2)$ \\
$\mathrm{Z}$ & $5171.6(9) \AA^{3}$ \\
Density (calculated) & 4 \\
Absorption coefficient & $1.735 \mathrm{mg} / \mathrm{m}^{3}$ \\
$\mathrm{~F}_{\text {(000) }}$ & $4.237 \mathrm{~mm}^{-1}$ \\
Index ranges & 2696 \\
Reflections collected & $-18 \leq \mathrm{h} \leq 18,-18 \leq \mathrm{k} \leq 17,-25 \leq 1 \leq 19$ \\
Independent reflections & $13189\left[\mathrm{R}_{\text {(int) }}=0.0407\right]$ \\
Data/restraints/parameters & 6375 \\
Goodness of fit indicator & $6375 / 2 / 577$ \\
$\mathrm{R}[\mathrm{I}>2 \sigma(\mathrm{I})]$ & 1.044 \\
Largest diff. peak and hole & $\mathrm{R}_{1}=0.0342, \mathrm{wR}_{2}=0.1109$ \\
\hline
\end{tabular}

\section{RESULTS AND DISCUSSION}

X-Ray crystallographic analysis reveals the crystal structure of the Ni(II) complex. The ORTEP representation of the $\mathrm{Ni}$ (II) complex is shown in Fig. 1. Selected bond lengths and angles are summarized in Table-2. The Ni(II) complex crystallizes in the monoclinic system, space group Cc, which consists of three $\mathrm{Ni}(\mathrm{II})$ atoms, two tetradentate $(\mu-\mathrm{L})^{2-}$ units, two coordinated $\mu$-acetate ions and two coordinated tetrahydrofuran molecules. Three hexa-coordinated Ni(II) atoms of the Ni(II) complex have a distorted octahedron. The two terminal $\mathrm{Ni}(\mathrm{II})$ atoms $(\mathrm{Ni} 2$ and $\mathrm{Ni3}$ ) are both located in the cis $-\mathrm{N}_{2} \mathrm{O}_{2}$ coordination cavity of the $(\mu-\mathrm{L})^{2-}$ unit and coordinated to the $\mathrm{O} 10$ (or $\mathrm{O} 12$ ) atom from the $\mu$-acetato ions and the $\mathrm{O} 13$ (or O14) atom from the THF molecule in the axial positions. The dihedral angle between the coordination plane of O3-Ni2-N1 and that of O4-Ni2-N2 is ca. 8.05(3) $)^{\circ}$, whereas that of O7-Ni3-N3 and O8-Ni3-N4 is about $10.63(2)^{\circ}$ indicating the formation of the distortion octahedral geometry around terminal $\mathrm{Ni}(\mathrm{II})$ atoms. Meanwhile, the coordination

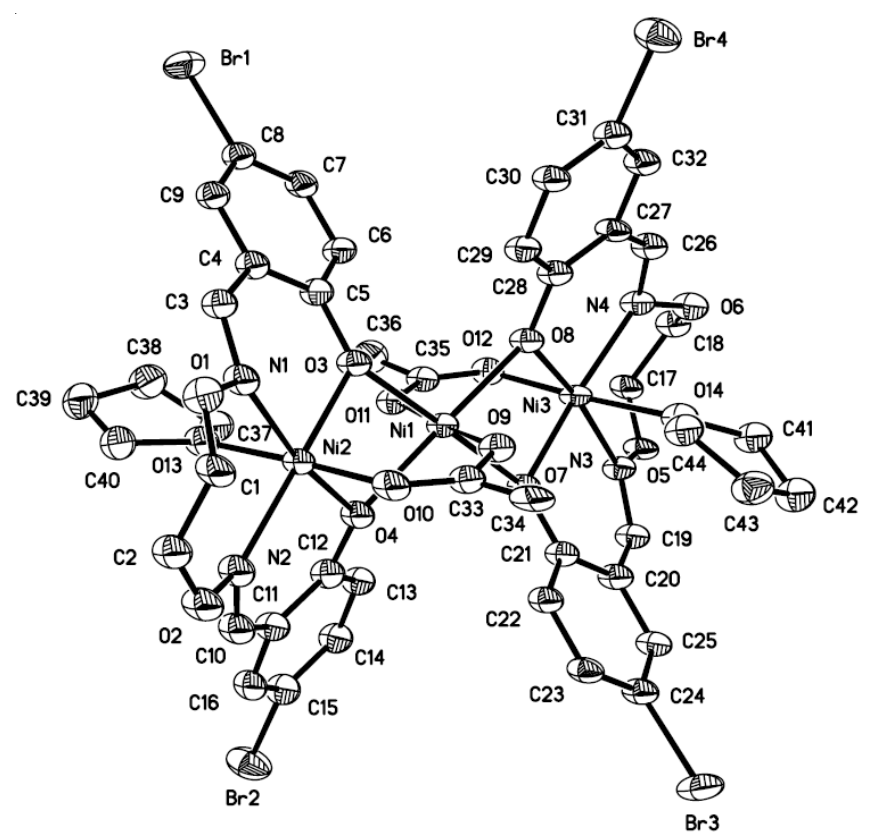

Fig. 1. Molecular structure of the Ni(II) complex with the atomic numbering

sphere of the central $\mathrm{Ni}(\mathrm{II})$ atom (Ni1) is completed by quadruple $\mu$-phenoxo oxygen atoms $(\mathrm{O} 3, \mathrm{O} 4, \mathrm{O} 7$ and $\mathrm{O} 8)$ from two $(\mu-\mathrm{L})^{2-}$ moieties and double $\mu$-acetato oxygen atoms (O9 and $\mathrm{O} 11$ ) which adopt a familiar $\mu-\mathrm{O}-\mathrm{C}-\mathrm{O}$ fashion. The dihedral angle between the coordinated planes O3-Ni1-O4 and O7-Ni1-O8 is $1.02(2)^{\circ}$, indicating the formation of the slight distortion octahedral geometry around central $\mathrm{Ni}(\mathrm{II})$ atoms. Furthermore, the distances of $\mathrm{Ni} 1 \cdots \mathrm{Ni} 2$ and $\mathrm{Ni} 1 \cdots \mathrm{Ni} 3$ are 3.117(3) $\AA$ and 3.112(3) $\AA$, indicating metal-metal bond or the metal surface electron spin exchange is not exist. The angles of Ni1-O3-Ni2 and Ni1-O8-Ni3 are 96.42(3) ${ }^{\circ}$ and 97.11(3) ${ }^{\circ}$, indicating $\mathrm{Ni}-\mathrm{O}-\mathrm{Ni}$ is non-collinar, thus not easy in electronic exchange.

In the crystal structure, the $\mathrm{Ni}(\mathrm{II})$ complex molecules are linked into an infinite 2D supramolecular layer structure

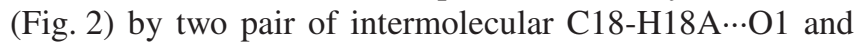
$\mathrm{C} 18-\mathrm{H} 18 \mathrm{~B} \cdots \pi_{\text {centroid (C11-C16) }}$ hydrogen-bonding interactions and lie in the accepted distance range for this type of contacts $(\text { Table-3) })^{11,12}$.

TABLE-2

SELECTED BOND LENGTHS $(\AA ̊)$ AND ANGLES $\left({ }^{\circ}\right)$ FOR THE Ni(II) COMPLEX

\begin{tabular}{cccccc}
\hline Bond & Lengths & Bond & Lengths & Bond & Lengths \\
\hline Ni1-O11 & $2.08(3)$ & Ni2-O10 & $1.99(3)$ & Ni3-O8 & $2.030(2)$ \\
Ni1-O9 & $2.10(3)$ & Ni2-O4 & $2.02(2)$ & Ni3-O12 & $2.06(3)$ \\
Ni1-O7 & $2.10(2)$ & Ni2-O3 & $2.06(2)$ & Ni3-O7 & $2.061(2)$ \\
Ni1-O3 & $2.12(2)$ & Ni2-N1 & $2.06(3)$ & Ni3-N4 & $2.10(3)$ \\
Ni1-O8 & $2.12(2)$ & Ni2-N2 & $2.10(3)$ & Ni3-N3 & $2.14(2)$ \\
Ni1-O4 & $2.15(2)$ & Ni2-O13 & $2.22(3)$ & Ni3-O14 & $2.23(3)$ \\
\hline Bond & Angles & Bond & Angles & Bond & Angles \\
\hline O11-Ni1-O9 & $178.1(9)$ & O4-Ni2-O3 & $82.1(8)$ & O8-Ni3-O7 & $81.4(8)$ \\
O7-Ni1-O3 & $178.4(1)$ & O4-Ni2-N1 & $167.2(9)$ & O8-Ni3-N4 & $92.0(9)$ \\
O7-Ni1-O8 & $78.4(8)$ & O3-Ni2-N1 & $85.5(9)$ & O7-Ni3-N4 & $168.1(1)$ \\
O3-Ni1-O8 & $103.2(8)$ & O4-Ni2-N2 & $90.4(9)$ & O8-Ni3-N3 & $169.1(9)$ \\
O7-Ni1-O4 & $100.7(8)$ & O3-Ni2-N2 & $169.8(1)$ & O7-Ni3-N3 & $88.0(8)$ \\
O3-Ni1-O4 & $77.7(8)$ & N1-Ni2-N2 & $101.5(1)$ & N4-Ni3-N3 & $98.0(1)$ \\
O8-Ni1-O4 & $178.8(1)$ & O10-Ni2-O13 & $177.8(9)$ & O12-Ni3-O14 & $176.9(8)$ \\
\hline
\end{tabular}




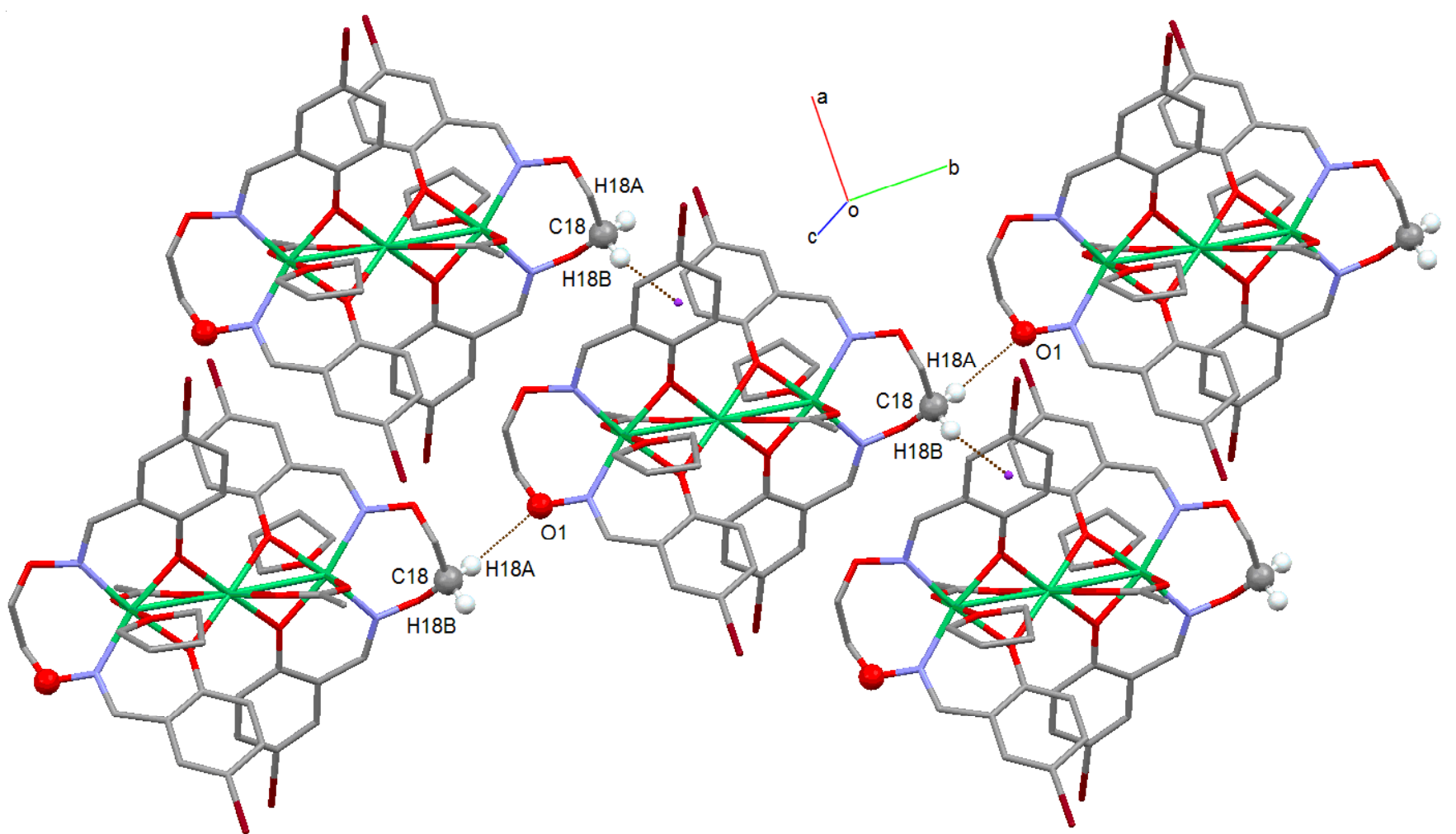

Fig. 2. View of the 2D supramolecular layer within the Ni(II) complex (hydrogen atoms, except those forming hydrogen bonds, are omitted for clarity)

\begin{tabular}{|c|c|c|c|c|}
\hline \multicolumn{5}{|c|}{$\begin{array}{c}\text { TABLE-3 } \\
\text { DATA FOR HYDROGEN-BONDING } \\
\text { AND C-H } \cdots \pi \text { INTERACTIONS }\left[\AA{ }^{\circ}{ }^{\circ}\right]\end{array}$} \\
\hline D-H $\cdots A$ & $d(D-H)$ & $\mathrm{d}(\mathrm{H} \cdots \mathrm{A})$ & $\mathrm{d}(\mathrm{D} \cdots \mathrm{A})$ & $\angle \mathrm{D}-\mathrm{H} \cdots \mathrm{A}$ \\
\hline 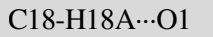 & 0.98 & 2.62 & $3.399(3)$ & 137 \\
\hline $\mathrm{C} 18-\mathrm{H} 18 \mathrm{~B} \cdots \mathrm{Cg} 1^{\mathrm{a}}$ & 0.97 & 2.97 & $3.900(4)$ & 160 \\
\hline
\end{tabular}

${ }^{\mathrm{a}} \mathrm{Cg} 1$ is the $\mathrm{C} 11-\mathrm{C} 16$ ring centroid.

\section{ACKNOWLEDGEMENTS}

The authors thank the Young Scholars Science Foundation of Lanzhou Jiaotong University (2011007) for financial support of this work.

\section{REFERENCES}

1. P.A. Karplus and M.A. Pearson, Acc. Chem. Res., 30, 330 (1997).

2. H.L. Zhu, L.M. Zheng, J. Zhao, W.M. Bu and W.X. Tang, Transition Met. Chem., 24, 131 (1999).
3. H.L. Zhu, Y.X. Tong, X.M. Chen and C.X. Ren, Transition Met. Chem., 26, 528 (2001).

4. W.K. Dong, L. Li, C.F. Li, L. Xu and J.G. Duan, Spectrochim. Acta A, 71, 650 (2008).

5. W.K. Dong, J.Y. Shi, L. Xu, J.K. Zhong, J.G. Duan and Y.P. Zhang, Appl. Organomet. Chem., 22, 89 (2008).

6. W.K. Dong, X.N. He, H.B. Yan, Z.W. Lv, X. Chen, C.Y. Zhao and X.L. Tang, Polyhedron, 28, 1419 (2009).

7. W.K. Dong, J.G. Duan, L.Q. Chai, G.L. Liu and H.L. Wu, J. Coord. Chem., 61, 1306 (2008).

8. W.K. Dong, Y.X. Sun, Y.P. Zhang, L. Li, X.N. He and X.L. Tang, Inorg. Chim. Acta, 62, 117 (2009).

9. G.M. Sheldrick, SHELXS97, Program for Crystal Structure Determination, University of Göttingen, Germany (1996).

10. G.M. Sheldrick, Acta Cryst., A64, 112 (2008).

11. W.K. Dong, J.H. Feng, L. Wang, L. Xu, L. Zhao and X.Q. Yang, Transition Met. Chem., 32, 1101 (2007).

12. H.L. Wu, R.R. Yun, K.T. Wang, K. Li, X.C. Huang and T. Sun, Z. Anorg. Allg. Chem., 636, 629 (2010). 